Vol. 1 No. 1, November 2021, /28-39 P-ISSN: 1978-4908

\title{
INCREASING AKIDAH AKHLAK LEARNING OUTCOMES THROUGH THE READING GUIDE METHOD
}

\author{
${ }^{1}$ Nor Hamidah ${ }^{2}$ Abdullah Sakka \\ Email: hamidahsby1977@gmail.com Coauthor:2abdullah_sakka@iaingorontalo.ac.id \\ ${ }^{1}$ MI Hasyim Asy'ari Sedati Sidoarjo, ${ }^{2}$ IAIN Sultan Amai Gorontalo, Indonesia
}

Article Info: Received: 03 Oktober 2021, Diseminarkan: 19 Oktober 2021 Published: 25 November 2021

\begin{abstract}
This study aims to determine the increase in learning outcomes after implementing the Reading Guide learning method. This research method uses Classroom Action Research with two cycle steps. The subjects of this study were students of class V-B MI Hasyim Asy'ari Pepe Sedati Sidoarjo. The data taken is the result of observing the implementation of learning and learning outcomes tests. Data analysis is as follows: 1) Pre-cycle: student learning outcomes are less satisfactory and student learning interest is less 2) Cycle I: learning process increases, student learning enthusiasm begins to focus, student interest in learning increases and student learning outcomes have increased. 3) Cycle II: the learning process increases, students' enthusiasm for learning begins to be directed, student interest in learning increases and student learning outcomes achieve the expected results.
\end{abstract}

Keywords: Reading Guide, Learning Outcomes, Akidah Akblak

\begin{tabular}{|l|}
\hline ABSTRAK \\
Penelitian ini bertujuan untuk mengetahui peningkatan hasil belajar setelah dilaksanakan \\
metode pembelajaran Reading Guide. Metode penelitian ini menggunakan Penelitian \\
Tindakan Kelas dengan langkah dua siklus. Subjek penelitian ini adalah siswa kelas V-B \\
MI Hasyim Asy'ari Pepe Sedati Sidoarjo. Data yang diambil adalah adalah hasil observasi \\
pelaksanaan pembelajaran dan tes hasil belajar. Analisis data sebagai berikut: 1) Pra siklus: \\
hasil belajar siswa kurang memuaskan dan minat belajar siswa kurang 2)Siklus I: proses \\
pembelajaran semakin meningkat, antusias belajar siswa mulai terarah, minat belajar siswa \\
meningkat dan hasil belajar siswa sudah meningkat. 3) Siklus II: proses pembelajaran \\
semakin meningkat, antusias belajar siswa mulai terarah, minat belajar siswa meningkat \\
dan hasil belajar siswa mencapai hasil yang diharapkan.
\end{tabular}

Kata Kunci : Reading Guide, Hasil Belajar, Akidah Akblak 


\section{PENDAHULUAN}

Hakekat belajar merupakan "proses berfikir, terjadi secara internal didalam diri seorang untuk memahami dan mendalami suatu kemampuan atau kompetensi atau keahlian tertentu baik yang kasat mata maupun yang abstrak". Hasil belajar merupakan hasil belajar yang dicapai setelah melalui proses kegiatan belajar mengajar. ${ }^{2}$ Hasil belajar dapat ditunjukkan melalui nilai yang diberikan oleh seorang guru dari jumlah bidang studi yang telah dipelajari oleh siswa. ${ }^{3}$ Setiap kegiatan pembelajaran tentunya selalu mengharapkan akan menghasilkan pembelajaran yang maksimal. Dalam proses pencapaiannya, hasil belajar sangat dipengaruhi oleh berbagai faktor. Salah satu faktor utama yang sangat berpengaruh dalam keberhasilan pembelajaran adalah keberadaan guru. Mengingat keberadaan guru dalam proses kegiatan belajar mengajar sangat berpengaruh, maka sudah semestinya kualitas guru harus diperhatikan. ${ }^{4}$

Penggunaan metode yang masih konvensional, dalam proses pembelajarannya guru masih belum memanfaatkan metode, media bantu atau alat peraga yang tepat. Kondisi ini berakibat pada suasana belajar yang kurang menyenangkan, motivasi belajar siswa menurun, sehingga hasil (hasil) belajar siswa menjadi rendah.

Salah satu pelajaran yang bisa membentuk akhlak siswa adalah pelajaran Aqidah Akhlak. Merupakan pendidikan yang sangat perlu untuk para siswa agar dapat mencerminkan dan menanamkan akhlak yang mulia di dalam jiwa anak dalam masa pertumbuhannya sehingga akhlak itu sebagai kemampuan jiwa. Di Madrasah Ibtidaiyah Akidah Akhlak merupakan salah satu mata pelajaran aqidah akhlak yang mempelajari tentang Perilaku Akhlak terpuji. Melalui pemberian contoh-contoh akhlak dan cara mengamalkannya dalam kehidupan sehari- hari. Secara substansial mata pelajaran Aqidah akhlak memiliki kontribusi dalam memberikan motivasi kepada siswa untuk mempraktekan al- akhlaqul karimah dan adab Islami dalam kehidupan sehari-hari sebagai manifestasi dari keimanannya kepada Alloh, malaikat-malaikatNya, kitab- kitab-Nya, rasul-rasul- Nya, hari akhir serta qada dan qodar. ${ }^{5}$

Penanaman nilai akidah akhlak dalam Islam bagi manusia merupakan hal yang sangat mendasar, karena itu nilai ini harus senantiasa ditanamkan sejak dini sampai dewasa. Kepribadian dan moral manusia sangat ditentukan oleh seberapa besar ajaran akidah akhlak tertanam dalam jiwanya, artinya apabila seseorang memperoleh pendidikan akidah akhlak dengan baik maka kemungkinan besar orang tersebut akan memiliki kepribadian dan moral yang baik. ${ }^{6}$ Sebaliknya apabila orang tersebut tidak memperoleh pendidikan akidah akhlak, maka besar kemungkinan akan kurang mantap kepribadian dan moralnya, karena pada prinsipnya tujuan umum pendidikan Islam diarahkan untuk mencapai pertumbuhan keseimbangan

\footnotetext{
${ }^{1}$ Sundari Sundari and Endang Fauziati, "Implikasi Teori Belajar Bruner Dalam Model Pembelajaran Kurikulum 2013,” PAPEDA : Jurnal Publikasi Pendidikan Dasar 03, no. 02 (2021): 128-36.

2 Marah Doly Nasution and Dinda Iriani Nasution, "Penerapan Model Pembelajaran Ropes (Review, Overview, Presentation, Exercise ,Summary) Untuk Meningkatkan Hasil Belajar Matematika Pada Siswa MTS Hifzhil Qur'an Medan," Education Journal of Indonesia 1, no. 1 (2020): 1-13, https://doi.org/https://doi.org/10.30596/eji.v1i1.575.

${ }_{3}^{3}$ Muhammad Syabrina and Sulistyowati Sulistyowati, "Pengembangan Media Pembelajaran Tematik Berbasis Macromedia Flash Untuk Meningkatkan Hasil Belajar Siswa Madrasah Ibtidaiyah,” Tarbiyah Wa Ta'lim: Jurnal Penelitian Pendidikan Dan Pembelajaran 7, no. 1 (2020): 25-36, https://doi.org/10.21093/twt.v7i1.2166.

${ }^{4}$ Ilmu Kependidikan, "Meningkatkan Prestasi Belajar Al-Qur'an-Hadis Melalui Metode Demonstrasi Pada Siswa Madrasah Aliyah," Al-Ta'dib 14, no. 1 (2021): 42-52.

${ }^{5}$ Khairul Bariah, "Pediamu: Jurnal Ilmu Pendidikan, Keguruan Dan Pengajaran 18," PediaMu 1, no. 1 (2021): 18-31.

${ }^{6}$ Usup Romli et al., "Pengembangan Media Pembelajaran Akidah Dengan Konsep 'Qurani’ Berbasis Ict Untuk Siswa Sekolah,” Jurnal Pendidikan Dan Pengajaran Guru Sekolah Dasar (JPPGuseda) 04 (2021): 60-64, http://journal.unpak.ac.id/index.php/jppguseda.
} 
kepribadian manusia menyeluruh, melalui latihan jiwa, intelek, jiwa rasional, perasaan, dan penghayatan lahir. Tujuan akhir pendidikan muslim itu terletak pada aktifitas merealisasikan pengabdian manusia seluruhnya.

Dalam pembelajaran ini peneliti mencoba untuk menggunakan metode Reading Guide agar siswa mampu menyerap dan memahami informasi baru secara cepat serta mempertahankan informasi tersebut. model pembelajaran Reading Guide dapat meningkatkan kemampuan belajar lebih efektif dalam menguasai bagaimana cara mempelajari sesuatu. ${ }^{\top}$ Belajar merupakan sesuatu yang bersifat alami, maka akan memberi kemudahan dalam mempelajarinya dan merupakan suatu proses yang berkesinambungan. Dalam belajar selalu ingin mendapatkan hasil yang sangat memuaskan diakhir pembelajaran, sehingga kita harus selalu mengali dan mengkaji serta mencari pengalaman-pengalaman baru dalam pembelajaran agar apa yang kita lakukan dapat meraih hasil yang maksimal.

Berdasarkan permasalahan tersebut di atas, maka peneliti bermaksud untuk mencari tahu dengan melakukan penelitian tindakan kelas dengan judul "Meningkatkan Hasil Belajar Akidah Akhlak Materi Akhlak Terpuji Melalui Metode Reading Guide"

Hasil penelusuran penulis ditemukan sejumlah riset yang berkemiripan dengan penelitian ini: 1) Skripsi yang ditulis oleh Sudati, "Penerapan Metode Guided Reading Dalam Upaya Meningkatkan Hasil Belajar Siswa Pada Mata Pelajaran Aqidah Akhlak Materi Akhlak Tercela Kelas V Mi Miftahul Falah Puncel Tahun Ajaran 2010/2011”.Tujuan penelitian tersebut lebih fokus kepada upaya mengetahui ada atau tidak peningkatan hasil belajar Aqidah Akhlak siswa kelas yang meliputi proses perencanaan, pelaksanaan, dan pelaporan. ${ }^{8}$ 2) Skripsi yang ditulis oleh Siti Rahmawati, "Upaya Meningkatkan Hasil Belajar Siswa Pada pelajaran Aqidah Akhlak Materi Akhlak terpuji Melalui Metode Sosiodrama di Kelas V.B MI Al-Islah Palembang”. Tujuan penelitian tersebut adalah untuk Mengetahui mengetahui dampak metode pelajaran sosiodrama terhadap hasil belajar materi akhlak terpuji mata aqidah akhlak pada siswa kelas V.B MI. AlIshlah Palembang.yang meliputi merencanakan (planning), melakukan tindakan (action), mengamati (observatian), dan merefleksi (reflektif), 3 ) Skripsi yang ditulis Muhammad Maizun, "Penerapan Model Reading Guide dalam Meningkatkan Hasil Belajar Siswa pada Mata Pelajaran Akidah Akhlak Kebudayan Islam Materi Pokok Kelahiran Nabi Muhammad SAW Kelas VII MI Cepiring Kec Cepiring Kab Kendal Tahun Pelajaran 2010/2011” Jenis peneitian ini adalah penelitian tindakan kelas (PTK), metode yang digunakan antara lain; observasi, dokumentasi dan test. Simpulan peneitian ini adalah pembelajaran menggunakan metode Reading Guide dapat meningkatkan hasil belajar pada siswa kelas VII pada mata pelajaran SKI materi Kelahiran Nabi Muhammad SAW, serta meningkatkan keaktifan siswa. ${ }^{10}$

Berdasarkan tiga sampel penelitian di atas, menunjukkan bahwa, Metode Reading Guide dalam meningkatkan pestasi belajar mata pelajaran aqidah akhlak belum semuanya diteliti, oleh

${ }^{7}$ Lasiati, "Meningkatkan Motivasi Belajar Peserta Didik Dengan Menerapkan Model Reading Guide Berbasis PAIKEM Lasiati," Jurnal Kependidikan 85, no. 1 (2016): 2071-79,

https://doi.org/https://doi.org/10.33394/jk.v2i1.431.

${ }^{8}$ Sudati. Penerapan Metode Reading Guide dalam Upaya Meningkatkan Meningkatkan Hasil Belajar Siswa pada Mata Pelajaran Aqidah Akhlak Pokok Bahasan Akhlak Tercela Kelas V MI Miftahul Falah Puncel Dukuhseti Pati Tahun Ajaran 2010/2011. Skripsi. https://eprints.walisongo.ac.id/id/eprint/2434

${ }^{9}$ Rahmawati Siti. . Upaya Meningkatkan Hasil Belajar Siswa Pada Pelajaran Aqidah Akhlak Materi Sikap Dermawan Melalui Metode Sosio Drama Di Kelas V Mi Al-Ishlah Palembang. Thesis. https://onesearch.id/Record/IOS3545.1555

${ }_{10}$ Maizun, M. Penerapan Model Reading Guide dalam Meningkatkan Hasil Belajar Siswa pada Mata Pelajaran Sejarah Kebudayan Islam Materi Pokok Kelabiran Nabi Mubammad SAW Kelas VII MI Cepiring Kec Cepiring Kab Kendal Tahun Pelajaran 2010/2011.

http://eprints.walisongo.ac.id/id/eprint/1175/https://www.rijal09.com/2016/03/pengertian-hasil-belajar.html 
karena itu fokus penelitian lebih diorientasikan pada apa yang dibutuhkan siswa dalam proses pembelajaran.Adapun alasan penulis tertarik mengajukan judul tersebut, karena Metode Reading Guide dapat meningkatkan hasil belajar siswa.

Data di lapangan menunjukkan bahwa tingkat keberhasilan siswa dapat dilihat dari hasil evaluasi atau tes pada akhir pembelajaran yang mencapai Kriteria Ketuntasan Minimal (KKM) atau lebih. Berdasarkan hasil pengamatan, apabila tingkat penguasaan siswa di bawah Kriteria Ketuntasan Minimal (KKM) maka perlu diadakan perbaikan pembelajaran, dan sebaliknya apabila tingkat penguasaan siswa diatas Kriteria Ketuntasan Minimal (KKM) maka perlu diadakan pengayaan. Dari pembelajaran mata pelajaran Aqidah Akhlak materi akhlak terpuji pada siswa kelas V MI Hasyim Asy'ari, dari 28 siswa, yang mendapat nilai mencapai Kreteria Ketuntasan Minimal atau lebih sebanyak 15 siswa atau 54\%. Selama pembelajaran berlangsung jarang siswa yang mengajukan pertanyaan atau memberi tanggapan terhadap penjelasan guru. Berdasarkan hal tersebut penulis meminta bantuan supervisor untuk mengidentifikasi kekurangan dari pembelajaran yang dilaksanakan. Itu disebabkan karena ada foktor yang mempengaruhi rendahnya hasil yang diperoleh siswa dalam pembelajaran. Dengan demikian maka penelitian ini tidak saja berupaya meningkatkan presetasi belajar, namun berorietasi keberhasilan pencapaian tujuan pembelajaran Akidah Akhlak agar dapat meningkatkan hasil belajar khusus pada materi akhlak terpuji bagi siswa kelas VB di MI Hasyim Asy'ari.

\section{METODE PENELITIAN}

Penelitian ini menggunakan metode Penelitian Tindakan Kelas (PTK) yang diterapkan pada kelas V MI Hasyim Asy'ari. Kecamatan Sedati Kabupaten Sidoarjo Provinsi Jawa Timur Model yang diterapkan dalam penelitian tindakan kelas ini adalah model yang dikemukakan oleh Kemmis dan Mc Taggar yaitu kegiatannya berbentuk siklus-siklus yaitu siklus I dan siklus II, mulai bulan Oktober sampai dengan November semester genap tahun ajaran 2020/2021

Penelitian dilaksanakan pada bulan Oktober dan November 2021 dengan subjek penelitian adalah siswa kelas V-B MI Hasyim Asy'ari Pepe Sedati Sidoarjo berjumlah 28 siswa. Teknik pengumpulan data menggunakan test, observasi, dan catatan lapangan. Teknik Analisis Data dilakukan dengan ketentuan sebagai berikut:

1. Sesuai dengan ketentuan sekolah siswa dinyatakan tuntas belajar dalam setiap tes jika nilai yang diperoleh 78, dengan nilai maksimal 100.

2. Adanya tes siswa yang dilakukan untuk mengetahui presentase ketuntasan belajar siswa dalam suatu kelas melalui penilaian berikut ini:

$$
\begin{array}{ll}
\mathbb{P}=\frac{F}{N} \times 100 \% & \text { Keterangan: } \\
& \mathrm{P}=\text { Persentase } \\
& \mathrm{F}=\text { Jumlah siswa yang mencapai } \\
& \text { ketuntasan } \\
& \mathrm{N}=\text { Jumlah seluruh siswa }
\end{array}
$$

Standar ketuntasan belajar siswa ditentukan dari hasil presentase penguasaan siswa pada kompetensi dasar dalam suatu materi tertentu. kriteria ketuntasan belajar setiap kompetensi dasar antara $0-100 \%$. Adapun untuk mengetahui nilai rata-rata siswa dilakukan melalui penilaian berikut ini:

$$
\bar{X}=\frac{\sum X}{N} \quad \text { Keterangan: }
$$




$$
\begin{array}{ll}
\bar{X} & =\text { Nilai rata-rata siswa } \\
\mathrm{N} & =\text { Jumlah siswa } \\
\Sigma \mathrm{X} & =\text { Jumlah nilai siswa }
\end{array}
$$

Menganalisa data aktivitas siswa dan guru melalui pengembangan skala likert dengan ketentuan skor nilai sebagai berikut:

$\begin{array}{ll}\text { Jawaban sangat baik diberi } & \text { skor } 5 \\ \text { Jawaban baik diberi } & \text { skor } 4 \\ \text { Jawaban cukup baik diberi } & \text { skor } 3 \\ \text { Jawaban kurang baik diberi } & \text { skor } 2 \\ \text { Jawaban tidak baik diberi } & \text { skor } 1\end{array}$

Cara menghitung presentase aktivitas siswa dan guru yaitu dengan menggunakan rumus sebagai berikut: $\mathrm{P}=\mathrm{F} / \mathrm{N} \times 100 \%$

Keterangan:

$$
\begin{array}{ll}
\mathrm{P} & =\text { Presentase } \\
\mathrm{F} & =\text { Frekuensi/total jawaban yang didapat } \\
\mathrm{N} & =\text { Jumlah maksimum }
\end{array}
$$

\section{HASIL DAN PEMBAHASAN}

\section{a. Kegiatan Pra Tindakan}

Jumlah peserta didik kelas V-B berjumlah 28 peserta didik yang. Kondisi peserta didik kelas V-B bersifat heterogen sama seperti kelas-kelas pada umumnya. Latar belakang keluarga peserta didik juga bermacam-macam diantaranya petani, pedagang, wiraswasta, dan pegawai.

Peneliti juga menjelaskan bahwa sebelum dilakukan penelitian akan dilakukan tes awal atau biasa disebut Pra Siklus. Sebelum pelaksanaan tindakan guru pengampu terlebih dahulu memperkenalkan peneliti di kelas V-B. Peneliti menyampaikan bahwa penelitian tersebut akan dilakukan dalam beberapa siklus, Setiap akhir siklus akan diadakan tes akhir tindakan untuk mengukur seberapa jauh keberhasilan tindakan yang telah dilaksanakan.

Pembelajaran Aqidah Akhlak yang dilaksanakan di kelas V B MI Hasyim Asy'ari Sedati - Sidoarjo cenderung menggunakan metode ceramah dan penugasan. Peserta didik cenderung pasif, mereka hanya mendengarkan penjelasan guru. Ini merupakan beberapa penyebab kejenuhan peserta didik dalam menerima pelajaran, sehingga berdampak pada hasil belajar peserta didik.

Adapun penjabaran kegiatan Pra Siklus dapat dijelaskan sebagai berikut:

1) Kegiatan awal peneliti memberikan salam, peneliti megajak peserta didik berdoa bersama-sama, peneliti mengabsen kehadiran peserta didik dan melakukan apersepsi untuk memberikan semangat pada peserta didik dan memberi tahu bahwa akan diadakan Pra Siklus.

2) Kegiatan inti peneliti mengkondisikan peserta didik untuk

3) Pra Siklus kepada peserta didik guna mengetahui sejauh mana tingkat pemahaman peserta didik berkaitan dengan materi yang diujikan.

4) Kegiatan akhir memberikan motivasi yang berguna untuk peserta didik, selain itu peneliti menginformasikan bahwa pertemuan selanjutnya akan berlangsung secara berpeserta didik. Peneliti sama dan mengucapkan salam. Selanjutnya peneliti melakukan koreksi terhadap lembar jawaban peserta didik untuk mengetahui hasil 
nilai Pra Siklus. Adapun nilai hasil Pra Siklus pelajaram Aqidah Akhlak kelas V-B dapat dilihat dalam tabel berikut:

Tabel 1.1 Rekapitulasi Hasil Pra Siklus

\begin{tabular}{|c|c|c|c|c|}
\hline NO & NAMA & KKM & NILAI & $\begin{array}{c}\text { TUNTAS/ } \\
\text { TIDAK TUNTAS }\end{array}$ \\
\hline 1 & Afrin Wulandari & 75 & 80 & Tuntas \\
\hline 2 & Al Zikri Amanu Hakiki & 75 & 50 & Tidak tuntas \\
\hline 3 & Ana Musabbichah & 75 & 60 & Tidak tuntas \\
\hline 4 & Aqeel Haidar Mulyaputra & 75 & 70 & Tidak tuntas \\
\hline 5 & Dewi Aulia Istifani & 75 & 70 & Tidak tuntas \\
\hline 6 & Dwi Puspa Maha Rani & 75 & 80 & Tuntas \\
\hline 7 & Fidela Azaria Dwi Hernomo & 75 & 70 & Tidak tuntas \\
\hline 8 & Kirana Annisa Putri & 75 & 70 & Tidak tuntas \\
\hline 9 & M Galih Mahardika Putri R. & 75 & 60 & Tidak tuntas \\
\hline 10 & Maulidiyyah Nadwatul 'Aqilah & 75 & 70 & Tidak tuntas \\
\hline 11 & Meilina Nabilan Nuha & 75 & 60 & Tidak tuntas \\
\hline 12 & Melysa Putri Agustin & 75 & 50 & Tidak tuntas \\
\hline 13 & Missyelin Rezki Alifia & 75 & 50 & Tidak tuntas \\
\hline 14 & Muhammad Fahmi Amrullah & 75 & 90 & Tuntas \\
\hline 15 & Muhammad Ansarullah W. & 75 & 80 & Tuntas \\
\hline 16 & Muhammad Faiz Fadlurrahman & 75 & 80 & Tuntas \\
\hline 17 & Muhammad Hafizh Rahman & 75 & 50 & Tidak tuntas \\
\hline 18 & Muhammad Roofiurrutab & 75 & 60 & Tidak tuntas \\
\hline 19 & Muhammad Shohibul Umam & 75 & 70 & Tidak tuntas \\
\hline 20 & Nadia Rahmahdani & 75 & 70 & Tidak tuntas \\
\hline & Nathan Maulana Aprilio Putra & 75 & 70 & Tidak tuntas \\
\hline & Nazidah Eka Aliyah & 75 & 100 & Tuntas \\
\hline & Putriana Nur Dina Mauliodiyah & 75 & 60 & Tidak tuntas \\
\hline 24 & Satria Bhakti Perdana & 75 & 80 & Tuntas \\
\hline 25 & Wardatul Jannah Istifadah & 75 & 50 & Tidak tuntas \\
\hline 26 & Yurcel Natha Favian & 75 & 50 & Tidak tuntas \\
\hline & Zahira Azza Azmiya Hadi & 75 & 60 & Tidak tuntas \\
\hline & Zahirah Alia Cinta Wijaya & 75 & 60 & Tidak tuntas \\
\hline & Jumlah Skor yang Diperoleh & \multicolumn{3}{|c|}{1.870} \\
\hline
\end{tabular}

Sumber : Hasil Nilai Pra Siklus 
Berdasarkan tabel 1.1 di atas, dapat diketahui dari 28 peserta didik yang mengikuti Pra Siklus, diperoleh data 7 dari 28 peserta didik mencapai ketuntasan belajar dan 21 dari 28 peserta didik tidak mencapai ketuntasan belajar.

Tabel 1.2 Analisis Hasil Pra Siklus

\begin{tabular}{c|lc}
\hline No. & \multicolumn{1}{|c|}{ Uraian } & Hasil Pra Siklus \\
\hline 1. & Jumlah peserta didik seluruhnya & 28 \\
\hline 2. & Jumlah peserta didik yang telah tuntas & 7 \\
\hline 3. & Jumlah peserta didik yang tidak tuntas & 21 \\
\hline 4. & Jumlah skor yang diperoleh & 1.870 \\
\hline 5. & Rata-rata nilai kelas & 67 \\
\hline 6. & Prosentase ketuntasan & $25 \%$ \\
\hline 7. & Prosentase ketidaktuntasan & $75 \%$ \\
\hline
\end{tabular}

Dari tabel di atas dapat diketahui nilai rata-rata peserta didik pada tes awal adalah 67 dengan prosentase ketuntasan belajar sebesar 25\%. Hasil tes sangat jauh dari yang diharapkan peneliti yaitu sebesar $80 \%$. Hasil tes awal ini nantinya akan digunakan peneliti sebagai acuan untuk peningkatan hasil belajar yang akan dicapai oleh peserta didik.

Data tes awal tersebut peneliti akan mengadakan penelitian tindakan kelas guna meningkatkan hasil belajar peserta didik dengan menerapkan metode Reading Guide pada mata pelajaran Aqidah Akhlak. Peneliti berharap dengan dengan diterapkannya metode Reading Guide pada pelajaran Aqidah Akhlak ini hasil belajar peserta didik mengalami peningkatan, sehingga ketuntasan kelas minimal dapat mencapai $80 \%$ dari jumlah keseluruhan peserta didik dengan nilai $\geq 75$.

Hasil penelitian selanjutkan dilakukan tindakan mulai siklus 1 dan 2 yang diuraikan dalam tahapan yang berupa siklus-siklus pembelajaran yang dilakukan dalam proses belajar mengajar di kelas. Dalam penelitian ini pembelajaran dilakukan dalam dua siklus sebagaimana pemaparan berikut ini :

\section{Siklus I dan II}

a. Perencanaan

1) Lembar observasi peneliti dan peserta

2) Menyusun rencana pelaksanaan pembelajaran,

3) Menyiapkan metode pembelajaran Reading Guide,

4) Menyusun lembar kerja individu dan peserta didik,

5) Menyiapkan lembar absensi,

6) Melakukan kegiatan pelaksanaan tindakan. ${ }^{11}$

\section{b. Pelaksanaan Tindakan}

1) Kegiatan Awal

a) Mengucap salam

${ }^{11}$ Arif Mustaqim and Ibnu Rawandhy N Hula, "INCREASING LEARNING OUTCOMES THROUGH," Journal:Education and Language Research Center(ELRC) 1, no. 1 (2021): 1-10, https://doi.org/https://doi.org/10.31219/osf.io/vgebx. 
b) Guru mengkondisikan kelas untuk belajar

c) Guru mengecek kehadiran siswa

d) Guru menyampaikan tujuan pembelajaran dengan materi Akhlak Terpuji

2) Kegiatan Inti

a) Guru menjelaskan tentang akhlak terpuji.

b) Guru memberikan pertanyaan tentang akhlak terpuji

c) Guru menunjuk siswa untuk megutarakan jawaban

3) Kegiatan apersepsi

4) Kegiatan Akhir
a) Guru dan siswa bersama-sama membuat kesimpulan
b) Guru memberikan evaluasi
c) Penutup

\section{b. Hasil Observasi dan Refleksi}

Tabel 1.3

Perbandingan Ketuntasan Belajar Pra Siklus, Siklus I dan Siklus II

\begin{tabular}{|c|c|c|c|c|c|}
\hline $\begin{array}{l}\mathbf{N} \\
\mathbf{O}\end{array}$ & NAMA & KKM & $\begin{array}{c}\text { NILAI } \\
\text { PRA } \\
\text { SIKLUS }\end{array}$ & $\begin{array}{l}\text { NILAI } \\
\text { SIKLUS I }\end{array}$ & $\begin{array}{c}\text { NILAI } \\
\text { SIKLUS } \\
\text { II }\end{array}$ \\
\hline 1 & Afrin Wulandari & 75 & 80 & 90 & 100 \\
\hline 2 & Al Zikri Amanu Hakiki & 75 & 50 & 70 & 80 \\
\hline 3 & Ana Musabbichah & 75 & 60 & 70 & 80 \\
\hline 4 & Aqeel Haidar Mulyaputra & 75 & 70 & 90 & 100 \\
\hline 5 & Dewi Aulia Istifani & 75 & 50 & 70 & 80 \\
\hline 6 & Dwi Puspa Maha Rani & 75 & 80 & 90 & 100 \\
\hline 7 & Fidela Azaria Dwi Hernomo & 75 & 70 & 80 & 90 \\
\hline 8 & Kirana Annisa Putri & 75 & 70 & 80 & 90 \\
\hline 9 & M Galih Mahardika Putri R. & 75 & 60 & 70 & 80 \\
\hline 10 & Maulidiyyah Nadwatul 'Aqilah & 75 & 70 & 70 & 80 \\
\hline 11 & Meilina Nabilan Nuha & 75 & 60 & 60 & 70 \\
\hline 12 & Melysa Putri Agustin & 75 & 50 & 80 & 90 \\
\hline 13 & Missyelin Rezki Alifia & 75 & 50 & 70 & 80 \\
\hline 14 & Muhammad Fahmi Amrullah & 75 & 90 & 100 & 100 \\
\hline 15 & Muhammad Ansarullah W. & 75 & 70 & 80 & 100 \\
\hline 28 & $\begin{array}{l}\text { Muhammad Faiz } \\
\text { Fadlurrahman }\end{array}$ & 75 & 80 & 90 & 100 \\
\hline 17 & Muhammad Hafizh Rahman & 75 & 50 & 70 & 90 \\
\hline 18 & Muhammad Roofiurrutab & 75 & 60 & 80 & 90 \\
\hline 19 & Muhammad Shohibul Umam & 75 & 70 & 80 & 90 \\
\hline 20 & Nadia Rahmahdani & 75 & 70 & 80 & 90 \\
\hline 21 & Nathan Maulana Aprilio Putra & 75 & 70 & 70 & 80 \\
\hline $\begin{array}{l}\mathbf{N} \\
\mathbf{O}\end{array}$ & NAMA & KKM & $\begin{array}{c}\text { NILAI } \\
\text { PRA }\end{array}$ & $\begin{array}{l}\text { NILAI } \\
\text { SIKLUS }\end{array}$ & $\begin{array}{l}\text { NILAI } \\
\text { SIKLUS }\end{array}$ \\
\hline
\end{tabular}




\begin{tabular}{l|l|c|c|c|c}
\hline & & SIKLUS & I & II \\
\hline 22 & Nazidah Eka Aliyah & 75 & 100 & 100 & 100 \\
\hline 23 & $\begin{array}{l}\text { Putriana Nur Dina } \\
\text { Mauliodiyah }\end{array}$ & 75 & 60 & 60 & 70 \\
\hline 24 & Satria Bhakti Perdana & 75 & 80 & 80 & 90 \\
\hline 25 & Wardatul Jannah Istifadah & 75 & 50 & 70 & 80 \\
\hline 26 & Yurcel Natha Favian & 75 & 50 & 70 & 80 \\
\hline 27 & Zahira Azza Azmiya Hadi & 75 & 60 & 70 & 80 \\
\hline 28 & Zahirah Alia Cinta Wijaya & 7 & 60 & 70 & 80 \\
\hline & & 5 & $\mathbf{2 1}$ & $\mathbf{1 4}$ & \\
\hline Jumlah peserta didik yang tidak tuntas & & $\mathbf{1 . 8 7 0}$ & $\mathbf{2 . 1 8 0}$ & $\mathbf{2 . 4 4 0}$ \\
\hline Jumlah skor yang diperoleh & & $\mathbf{6 7}$ & $\mathbf{7 7 , 5}$ & $\mathbf{8 7}$ \\
\hline Rata-rata nilai kelas & & $\mathbf{2 5 \%}$ & $\mathbf{5 0} \%$ & $\mathbf{9 3} \%$ \\
\hline \multicolumn{2}{l}{ Prosentase ketuntasan } \\
\hline
\end{tabular}

\section{Gambar 1}

\section{Perbandingan Ketuntasan Belajar Pra Siklus, Siklus I dan Siklus II}

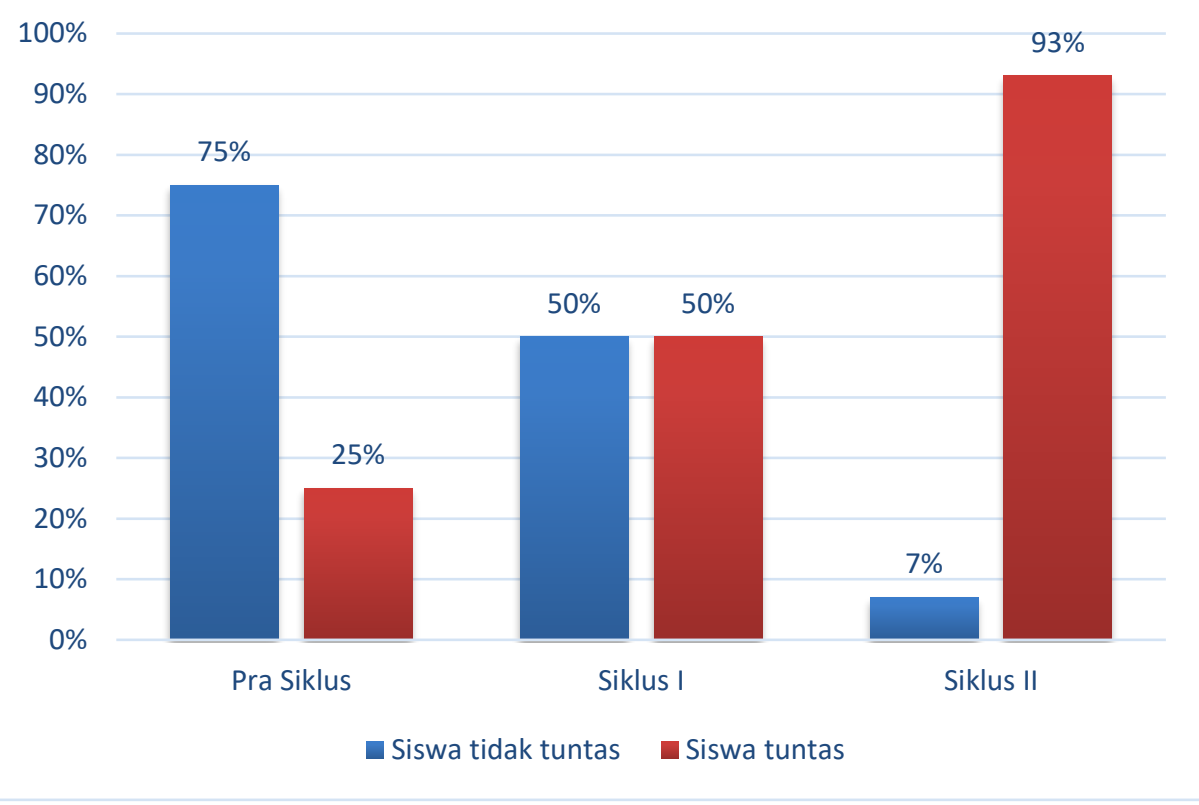

Hasil belajar peserta didik berdasarkan hasil siklus II menunjukkan peningkatan dibandingkan dengan hasil siklus I. Terbukti dari nilai rata pada siklus I 77,5 meningkat pada saat siklus II menjadi 87. Hal ini juga beriringan dengan peningkatan ketuntasan belajar peserta didik, meningkat dari 50\% menjadi 93\%. Dengan demikian, peresentase ketuntasan belajar peserta didik sudah mencapai kriteria ketuntasan yang telah ditetapkan, yaitu sebesar $80 \%$ dari keseluruhan jumlah peserta didik yang mengikuti tes.

Terlihat dari peningkatan yang diperoleh pada setiap siklusnya, pada saat prasiklus atau sebelum dilakukannya tindakan nilai rata-rata 67 dengan jumlah murid yang berhasil 7 orang 
siswa ( $25 \%$ ) dari jumlah keseluruhan siswa yang mengikuti proses pembelajaran sebanyak 28 orang siswa Kemudian setelah dilakukannya tindakan siklus I (pertama) nilai rata-rata siswa yaitu 77,5 dengan jumlah siswa yang telah berhasil 14 orang (50\%) dari 28 orang siswa yang mengikuti proses pembelajarann. Dan meningkat lagi pada siklus II (kedua) dengan nilai ratarata 89 dan jumlah siswa yang berhasil 26 orang siswa (93\%) dari 28 siswa yang mengikuti proses pembelajaran.

\section{PENUTUP}

Dengan penerapan media pembelajaran Reading Guide dapat meningkatkan hasil belajar siswa pada mata pelajaran Akidah Akhlak kelas V MI Hasyim Asy'ari Kecamatan Sedati dan sangat dianjurkan sekali kepada wali kelas atau guru mata pelajaran yang mengajar untuk menggunakan media pembelajaran Reading Guide ini karena secara nyata dapat meningkatkan hasil belajar siswa dan memberikan variasi dalam mengajar yang membuat siswa antusias secara aktif dan saat mengkuti pembelajaran. Hal ini harus didukung dengan syarat, bahwa jika model pembelajaran Reading Guide dilaksanakan dengan baik sesuai dengan tahapantahapan ditetapkan dan didukung oleh kreatifitas guru dalam mengembangan materi dan bahan ajar Aqidah Akhlak sebagaimana yang diamanahkan dalam kurikum KMA $183 .{ }^{12}$

\section{DAFTAR PUSTAKA}

Bariah, Khairul. "Pediamu: Jurnal Ilmu Pendidikan, Keguruan Dan Pengajaran 18." PediaMu 1, no. 1 (2021): 18-31.

Kependidikan, Ilmu. "Meningkatkan Prestasi Belajar Al-Qur'an-Hadis Melalui Metode Demonstrasi Pada Siswa Madrasah Aliyah." Al-Ta'dib 14, no. 1 (2021): 42-52.

Lasiati. "Meningkatkan Motivasi Belajar Peserta Didik Dengan Menerapkan Model Reading Guide Berbasis PAIKEM Lasiati." Jurnal Kependidikan 85, no. 1 (2016): 2071-79. https://doi.org/https://doi.org/10.33394/jk.v2i1.431.

Mustaqim, Arif, and Ibnu Rawandhy N Hula. "INCREASING LEARNING OUTCOMES THROUGH.” Journal:Education and Language Research Center(ELRC) 1, no. 1 (2021): 1 10. https://doi.org/https://doi.org/10.31219/osf.io/vgebx.

Nasution, Marah Doly, and Dinda Iriani Nasution. "Penerapan Model Pembelajaran Ropes (Review, Overview, Presentation, Exercise ,Summary) Untuk Meningkatkan Hasil Belajar Matematika Pada Siswa MTS Hifzhil Qur'an Medan.” Education Journal of Indonesia 1, no. 1 (2020): 1-13. https://doi.org/https://doi.org/10.30596/eji.v1i1.575.

Romli, Usup, Dina Mayadiana Suwarma, Mohammad Rindu Fajar Islamy, and Muhamad Parhan. "Pengembangan Media Pembelajaran Akidah Dengan Konsep 'Qurani' Berbasis Ict Untuk Siswa Sekolah.” Jurnal Pendidikan Dan Pengajaran Guru Sekolab Dasar (JPPGuseda) 04 (2021): 60-64. http://journal.unpak.ac.id/index.php/jppguseda.

Sundari, Sundari, and Endang Fauziati. "Implikasi Teori Belajar Bruner Dalam Model Pembelajaran Kurikulum 2013.” PAPED A : Jurnal Publikasi Pendidikan Dasar 03, no. 02 (2021): 128-36.

Syabrina, Muhammad, and Sulistyowati Sulistyowati. "Pengembangan Media Pembelajaran Tematik Berbasis Macromedia Flash Untuk Meningkatkan Hasil Belajar Siswa Madrasah Ibtidaiyah." Tarbiyah Wa Ta'lim: Jurnal Penelitian Pendidikan Dan Pembelajaran 7, no. 1 (2020): 25-36. https://doi.org/10.21093/twt.v7i1.2166.

12 Mustaqim and Hula. 
Syafi'i, A., Marfiyanto, T., \& Rodiyah, K. S. (2018). Studi Tentang Hasil Belajar Siswa dalam Berbagai Aspek dan Faktor yang Mempengaruhi. Jurnal Komunikasi Pendidikan, 2(2).

Putri, K., Djaja, S., \& Suyadi, B. (2017). Pengaruh Minat Belajar Dan Kecerdasan Emosional Terhadap Hasil Belajar Siswa Kelas Xi Ips Sma Negeri 1 Prajekan Kabupaten Bondowoso Tahun Ajaran 20162017. Jurnal Pendidikan Ekonomi, 11(I).

Kurniawati, F. (2015). Pengembangan Bahan Ajar Aqidah Ahklak di Madrasah Ibtidaiyah. In Jurnal Penelitian (Vol. 9, Issue 2).

Simanullang, N. (2012). Hubungan Persepsi Tentang Kemampuan Guru Mengelola Pembelajaran Dan Motivasi Belajar Aqidah Akblak Dengan Kepatuhan Siswa Sekolah Di Man 2 Model Medan.

Zuhari, A. E., Djumhana, N., \& Mulyasari, E. (2018). Penerapan Metode Guide Reading Untuk Meningkatkan Kemampuan Membaca Pemahaman Siswa IV SD. In Jurnal Pendidikan Guru Sekolah Dasar: Vol. III No. II.

Sudati. (2011). Penerapan Metode Reading Guide dalam Upaya Meningkatkan Meningkatkan Hasil Belajar Siswa pada Mata Pelajaran Aqidah Akhlak Pokok Bahasan Akhlak Tercela Kelas V MI Miftahul Falah Puncel Dukuhseti Pati Tahun Ajaran 2010/2011. Skripsi. https://eprints.walisongo.ac.id/id/eprint/2434

Rahmawati SIti. (2017). Upaya Meningkatkan Hasil Belajar Siswa Pada Pelajaran Aqidah Akhlak Materi Sikap Dermawan Melalui Metode Sosio Drama Di Kelas V Mi Al-Ishlah Palembang. Thesis. https://onesearch.id/Record/IOS3545.1555

Maizun, M. (2012). Penerapan Model Reading Guide dalam Meningkatkan Hasil Belajar Siswa pada Mata Pelajaran Sejarah Kebudayan Islam Materi Pokok Kelabiran Nabi Muhammad SAW Kelas VII MI Cepiring Kec Cepiring Kab Kendal Tabun Pelajaran 2010/2011. http://eprints.walisongo.ac.id/id/eprint/1175/https://www.rijal09.com/2016/03/p engertian-hasil-belajar.html

Sukardi. (2014). Peningkatan Hasil Belajar Siswa Menggunakan Metode Percobaan Dalam Pembelajaran IP A Di Sekolah Dasar.

Alviana. (2013). Efektifitas model speaking stick dalam pembelajaran biologi materi fungsi dan struktur tumbuhan yang terintegrasi al-Quran surat al-An'am terhadap hasil belajar siswa kelas XI IPA MA Hidayatus Syubban Semarang. Skripsi. http://eprints.walisongo.ac.id/id/eprint/1681/

Sutomo, Moh. (2019). Penerapan Reading Guide Dalam Pembelajaran Di Madrasah. Auladuna: Jurnal Prodi Pendidikan Guru Madrasab Ibtidaiyah, 1(1). https://doi.org/10.36835/au.v1i1.169

Lestari. (2014). Pengaruh Metode Guide Reading Terhadap Hasil Belajar Mata Pelajaran AlQur'an Hadis Siswa Kelas V Min 2 Tanjung Raya Kecamatan Sukau Kabupaten Lampung Barat Tahun Pelajaran 2013/2014. Skripsi.

https://www.bungfei.com/2019/10/metode-pembelajaran-reading-guide.html Mahdum. (2020). Buku Akidah Akhlak Kelas V. Buku.

http://zonaislamterkini.blogspot.com/2017/02/akhlak-terpuji-teguh-pendirian.html \ https://www.republika.co.id/berita/q8wtzs430/kisah-kedermawanan-abu-bakar-ashshiddiq

https://id.wikipedia.org/wiki/Tawakal

Khasinah, S. (2013). Classroom Action Research. In Jurnal Pionir (Vol. 1, Issue 1).

Juanda, A. (2016). Penelitian Tindakan Kelas. Buku. 